\title{
LA CONVENIENCIA DE ESTABLECER EL SISTEMA DE JURADO EN LA JUSTICIA PENAL DE LOS PAÍSES PERIFÉRICOS HISPANOAMERICANOS
}

\section{THE CONVENIENCE TO ESTABLISH OF THE JURY SYSTEM IN CRIMINAL JUSTICE OF HISPANIC AMERICANS PERIPHERAL COUNTRIES}

\author{
Dr. Dr. Dr. H.c. Gino Ríos Patio \\ Director del Instituto de Investigación Jurídica \\ de la Universidad de San Martín de Porres \\ griosp@usmp.pe \\ Perú \\ Mg. Augusto Espinoza Bonifaz \\ Profesor de la Facultad de Derecho \\ de la Universidad de San Martín de Porres \\ aespinozab@usmp.pe \\ Perú
}

\section{SUMARIO}

- Introducción

- Origen y evolución de la potestad estatal de administrar justicia penal

- Análisis crítico del sistema togado de administración de justicia penal

- Hacia una verdadera democratización de la definición, asignación y ejecución de la conducta desviada

- Conclusiones

\section{RESUMEN}

Este artículo parte del precario índice de credibilidad y el alto índice de corrupción que muestra la administración de justicia en el Perú y los demás países periféricos de la región. Sin lugar a dudas, esta realidad constituye un grave problema de fragilidad e inestabilidad institucional en democracia situación a partir de la cual se analiza críticamente la conveniencia de establecer el sistema de justicia penal mediante jurado en los países periféricos a fin de garantizar su eficaz funcionamiento $\mathrm{y}$ terminar con el actual sistema de justicia togada que resulta infructuoso para contribuir al mantenimiento de la paz social, por su carácter sesgado, altamente selectivo, odiosamente discriminador y reproductor de la violencia con el agravante que tiene como autor al Estado. El objetivo central del artículo radica en demostrar la necesidad de un cambio cultural y de concienciación de la ciudadanía en los países periféricos de la región para mudar de sistema de administración de justicia penal, de uno togado y supuestamente representativo, pleno de ilegitimidad, a uno no togado pero genuinamente democrático, el cual solo podrá ser eficaz, según se concluye, si se planifica convenientemente la preparación y capacitación cívica en términos de ecuanimidad, imparcialidad, igualdad, equidad, firmeza, rectitud y probidad para el adecuado funcionamiento del nuevo sistema.

\section{ABSTRACT}

This article starts with the precarious index of credibility and the high level of corruption shown by the administration of justice in Peru and the other peripheral countries of the region, which undoubtedly constitutes a serious problem of fragility and institutional instability in democracy; situation from 
which it critically analyzes the advisability of establishment of the criminal justice system by means of a jury in the peripheral countries, in order to guarantee its effective functioning and to end the current system of tried justice that is unsuccessful to contribute to the maintenance of social peace, because of its biased, highly selective, hatefully discriminating and reproductive character of violence, with the aggravating factor that has as its author the State. The central objective of the article is to demonstrate the need for a cultural change and awareness of citizenship in the peripheral countries of the region, to move from a system of criminal justice administration, from one toghete and supposedly representative, full of illegitimacy, to one who is not tacit but genuinely Democratic, which can only be effective, it is concluded, if civic training and preparation in terms of equanimity, impartiality, equality, equity, firmness, rectitude and probity, is properly planned for the proper functioning of the new system.

\section{PALABRAS CLAVE}

Justicia penal, justicia togada, ilegitimidad de la justicia penal, justicia penal por jurado

\section{KEYWORDS}

Criminal justice, Justice, Illegitimacy of criminal justice, Criminal justice by jury

\section{INTRODUCCIÓN}

La opinión de la ciudadanía sobre las instituciones de la democracia formal en el Perú, entre las que naturalmente se encuentran aquellas vinculadas con el sistema de justicia, revela un alto índice de desconfianza que se incrementa cuando se trata de las instituciones del sistema de justicia como el Poder Judicial, el Ministerio Público y la Policía Nacional, así como del Poder Ejecutivo, cuyo Ministerio de Justicia comprende al Instituto Nacional Penitenciario y el Congreso de la República, que es el productor de las leyes, entre otros.

En efecto, según la encuesta de El Comercio hecha por Ipsos Perú, publicada el 20 de setiembre de 2015, el Poder Judicial continúa desacreditado, sus polémicos fallos y su lentitud hacen que un $79 \%$ no le tenga confianza; la Fiscalía de la Nación registra un
$70 \%$ de descrédito y la Policía Nacional un $55 \%$. En el caso del Poder Ejecutivo la tasa de desdoro se eleva al $73 \%$ y en el caso del Congreso de la República el ratio de demérito asciende al 84 \%. (Mejía, 2015, párr. 1)

Por otra parte, según la encuesta del diario Correo hecha por CPI, publicada el 3 de octubre de 2015, el Congreso de la República tiene una desaprobación de $85.1 \%$ y el Poder Judicial de $82.8 \%$, mientras que el Instituto Nacional Penitenciario llega al $53.9 \%$ de desaprobación y la Policía Nacional al 52.6 \%. (Correo, 2015, párr. 2, 6 y 7)

En América Latina en el 2016, Latinobarómetro registra que el Poder Judicial exhibe un magro $26 \%$ de confianza ciudadana, el Congreso un $25 \%$, el Gobierno un $28 \%$ y la Policía un $38 \%$. (Corporación Latinobarómetro, 2016, p. 32)

En la última edición del Barómetro de las Américas, del Proyecto de Opinión Pública de América Latina (LAPOP, por sus siglas en inglés), a mayo de 2015, Paraguay es el país de América con menor confianza ciudadana en el sistema judicial con $32,7 \%$, seguido del Perú con $35,5 \%$ y de Ecuador con $38,6 \%$. Luego, vienen Haití (39.6\%), Bolivia (40.4\%), Argentina (41.1\%), Venezuela $(41.9 \%)$, Trinidad y Tobago $(42.6 \%)$, Chile $(44.1 \%)$, Guatemala (44.4\%). (Infobae, 2015, párrs. 2 y 3)

Con semejantes datos, una apreciación panorámica de la ilegitimidad con la que desarrollan sus actividades estas instituciones, remite necesariamente al punto de partida del funcionamiento del sistema de justicia, marcado por una normatividad - a cargo del Congreso de la Repúblicaque la ciudadanía considera alejada de sus intereses generales; una operatividad -a cargo del Ministerio Público, el Poder Judicial y la Policía Nacional- que la población cree selectiva, injusta y discriminadora; y una coacción y/o ejecución de lo decidido normativa y jurisdiccionalmente - a cargo del Poder Ejecutivo- que la sociedad conceptúa abusiva y arbitraria.

El problema, vinculado a los aspectos centrales de justicia, seguridad y representación política, siendo evidente, permanece sin embargo naturalizado debido a su insufrible cotidianidad y a un rasgo sui generis de las 
de los países periféricos hispanoamericanos

The convenience to establish of the jury system in criminal justice of

hispanic americans peripheral countries

sociedades de nuestros países periféricos, como es su conformidad, resignación o desdén políticos que impide contribuir con la mejora o la transformación de aspectos lacerantes de su realidad nacional.

La actitud ciudadana respecto a la res publica es la del nada funciona, motivo por el que optan por adoptar medidas colaterales e irregulares o informales marginales para seguir operando como sociedad. Claro que en los intersticios de tales medidas aparecen eventualmente situaciones como las de la denominada justicia popular o justicia por mano propia, que en América Latina tienen una alta aprobación según la medición hecha por Latinobarómetro, ascendente al $32 \%$ en el 2014 y constituyen un riesgo serio para la afectación de los derechos fundamentales, que de expandirse o también de no utilizarse, crearían las condiciones necesarias para que sobrevenga el caos, la anomia y la ingobernabilidad con lo cual se afectaría la seguridad integral de la población. (LAPOP, 2014)

En otras palabras, dichos aspectos de justicia, seguridad y representación política están definidos por el ejercicio del poder punitivo, entonces entre los principales objetivos de esta investigación están demostrar que el funcionamiento del sistema de justicia con base en magistrados togados refuerza el poder punitivo orientado al mantenimiento del control y la dominación existentes y que la población rechaza; acreditar que dicho sistema no ha sido eficaz históricamente, lo que se verifica por el elevado número de ciudadanos privados de la libertad a enero de $2016(93,210)$ y ciudadanos internos en establecimientos penitenciarios sin condena $(39,100$ a la misma fecha), así como por el porcentaje de reingresantes a la cárcel a esa fecha (21\%); y dejar sentada la necesidad de iniciar un proceso de cambio en el modelo de justicia a fin de que se instale un sistema de jurados, previa concienciación y capacitación ciudadana. (INPE, 2016, pp. 4 y 37)

En ese sentido la investigación se justifica por su importancia teórica y utilidad social, por cuanto el problema es trascendente para alcanzar la paz social en justicia por medio de la resolución de conflictos con una genuina participación ciudadana a la que hay que concienciar y capacitar para que actúen responsablemente en la labor de administración de justicia como jurados.
En el desarrollo de la investigación, luego de la introducción al problema que se verá en el capítulo primero, se analizará en el capítulo segundo el origen y evolución de la potestad estatal de administrar justicia penal exponiendo el significado de la justicia y su importancia para un Estado constitucional, democrático y de derecho. En el capítulo tercero se efectúa un análisis crítico de la administración de justicia penal destacando la visión del crimen y castigo en las sociedades de los países periféricos hispanoamericanos. En el capítulo cuarto se evalúan los sistemas judiciales togados $\mathrm{y}$ por jurados en función de sus ventajas y desventajas y se presenta la visión y propuesta de los autores hacia una verdadera democratización de la definición, asignación y ejecución de la conducta desviada. En el capítulo quinto se propone la concienciación y capacitación previas de la ciudadanía para cambiar de modelo. Finalmente, se muestran las conclusiones y recomendaciones.

\section{ORIGEN Y EVOLUCIÓN DE LA POTESTAD ESTATAL DE ADMINISTRAR JUSTICIA PENAL}

\section{Origen y evolución}

En Europa, a partir del siglo XIII, el Estado confiscó el conflicto a la víctima al producirse un cambio trascendental en las relaciones de poder en la sociedad, como lo sostiene Anitua (2015), y a partir de ese momento la determinación de la verdad legal a través del proceso penal se hizo mediante el método inquisitivo, es decir, la averiguación por medio de la violencia que ejerce el Estado como parte dominante sobre el súbdito dominado.

Ese hecho marcó definitivamente la forma de ejercer el poder punitivo y de hacer política criminológica, pues la autoridad estatal, entonces absolutista, podía dictar leyes y aplicarlas, atributo cuyo ejercicio podía cambiar las relaciones sociales.

Los jueces -y también la policía- como funcionarios de la autoridad, surgen por la necesidad de especialización que exigía este nuevo atributo estatal de ejercer el poder punitivo, con lo cual, afirma Anitua (2015), el derecho se perfiló coercitivo al asignar a la autoridad estatal un patrón de culpabilidad o inocencia prestablecido en función de las leyes 
sancionadas por el propio Estado. Más tarde surgiría la profesionalización y burocratización como órganos institucionalizados que se encargan de administrar la justicia penal, siempre desde la cúspide del poder, haciendo prevalecer desde entonces las ideas de orden y justicia en vez de la idea de libertad como consecuencia de la expansión de los estados y su conversión en formas organizativas concentradas, forma que requería de una organización dirigida por una autoridad central soberana.

Como se puede apreciar, la idea era mantener un poder político unificado. Los modos eran varios, entre ellos reclutar funcionarios instruidos para discernir justicia penal en nombre del monarca y ejercer violencia en nombre del Estado, con lo cual se trataría de una violencia legitimada. La manera en que los funcionarios profesionales ministraban justicia generó un discurso o pensamiento racionalizador que cerró el círculo de dominación consistente en idea y acción para un mismo fin, como era que el Estado reemplace al ciudadano en el conflicto intersubjetivo, a la sociedad reunida en asamblea para propiciar la resolución del conflicto y a la víctima para su resarcimiento.

Esta forma hegemónica para administrar justicia reveló que el daño causado por una conducta ya no importaba en medio del conflicto, sino la desobediencia, indisciplina y la falta de respeto a la ley de la autoridad soberana que había previamente predeterminado las conductas delictivas y el castigo a imponerse. Por eso el Estado intervenía en el conflicto particular para castigar el quebrantamiento de la norma dictada por él, no para hacer que se repare a la víctima, de ahí que surja el fiscal como representante del Estado en el conflicto, hoy denominado eufemísticamente defensor de la sociedad.

Eliminadas las partes de su propio conflicto, la víctima se convirtió en la gran olvidada del proceso penal, mientras que el infractor en el reo, palabra proveniente del latín res que significa cosa u objeto, es decir, perdió su calidad de persona sujeto de derecho.

Es inocultable, desde entonces, la vinculación entre el poder político y el poder económico a través del poder punitivo que beneficiaba (y beneficia) a la clase económicamente poderosa (burguesía) para conservar su posición de dominio privado.
A partir del siglo XVI hasta el siglo XVIII, sostiene Pavarini (2010), nuevamente un fenómeno económico social denominado acumulación originaria, genera en la segunda mitad del siglo XVIII la Revolución industrial, que pone fin al viejo orden sociopolítico feudal e instaura un nuevo orden capitalista caracterizado por la libertad del ciudadano como condición indispensable para su actividad comercial e industrial, que le permitía despojar a las clases productoras de los medios de producción y, con ello, afectar su sustento, por lo que se volvieron una fuerza de trabajo asalariada a la que había que disciplinar para que acepten su condición como natural e irreversible a fin de que la burguesía conserve su poder.

Esta vez el discurso racionalizador fue el contrato social, en virtud del cual se pretendió justificar el derecho de castigar sobre la existencia de un pacto tácito de los hombres que viven en sociedad mediante el cual cambian una porción de libertad por un orden social administrado por la autoridad estatal que de esa manera pasa de nuevo a erigirse y mantenerse como el único titular del poder punitivo, aunque con limitaciones propias derivadas de la ideología liberal como el principio de legalidad penal (solo la autoridad decidía criminalizar conductas), el principio de irretroactividad de la ley penal (solo podía regir para el presente y futuro) y el principio de retribución (la sanción debía ser proporcional al daño ocasionado).

El liberalismo permaneció durante los siglos XIX y XX pretendiendo hacer creer que traía consigo la igualdad entre los hombres, sin embargo, ello no fue así y solo conllevó injusticia, discriminación y exclusión social agudizadas en las postrimerías del siglo xx con el neoliberalismo, es decir, con la hipérbole de la libertad económica y el ocaso de las demás libertades. Entretanto, el ejercicio del poder punitivo continuó en manos del Estado en estrecha vinculación con el poder económico, con el concurso de profesionales abogados que se alejan del sentido común, el sentido de justicia y del conocimiento del género humano, merced a su apego a dogmas penales y discursos justificadores de la estructura y operatividad del sistema penal, alejados totalmente del verdadero titular del poder punitivo que es el pueblo como constitucionalmente está establecido. 
de los países periféricos hispanoamericanos

The convenience to establish of the jury system in criminal justice of

hispanic americans peripheral countries

\section{Crítica de la nueva criminología al poder punitivo}

La nueva criminología sostiene que el delito es una construcción sociopolítica dirigida especialmente a la clase marginal, vulnerable y desprotegida con la finalidad de mantener el statu quo, por lo que protege intereses de la minoría. En ese sentido, la imagen tradicional del delincuente permitió derivar, selectivamente, la agresividad del sistema penal a las clases bajas para que sus actos y no los de las clases poderosas sean perseguidos y sancionados como delictivos.

Así, explicó la manera cómo actuaban los mecanismos sociopolíticos y los intereses que promueven la creación de normas penales considerando el Derecho como la superestructura determinada por la organización social clasista, por eso acude a sancionar y reprimir los síntomas pero no elimina las causas.

La desviación no es una cualidad ontológica de ciertas conductas humanas y determinados individuos, es un status nocivo asignado a ciertas personas a las que el sistema punitivo etiqueta y estigmatiza por medio de la selección de los bienes protegidos legalmente, los comportamientos ofensivos y de la elección de determinados individuos estigmatizados entre todos los que cometen infracciones.

Por ello, la crítica al poder punitivo afirma la necesidad de transformar las estructuras socioeconómicas y políticas de la sociedad para reconocernos más iguales y hacer la convivencia más igualitaria, justa y digna, lo cual si bien no eliminará el crimen, cuando menos lo reducirá y controlará en su prevención con intervenciones positivas exentas de violencia y exclusión.

Concurrimos con Serrano (2017) cuando afirma que en la sociedad hay dos factores importantes que guardan relación con la conflictividad y la desviación del comportamiento: la cooperación, mediante la cual se busca un equilibrio entre los ciudadanos; y la competencia, con la cual cada uno busca la forma de conseguir recursos. Por ello, si existiera mayor cooperación e igualdad en la sociedad, la conflictividad y desviación sería menor; así como si existieran menos dificultades y más medios disponibles para la competencia, la conflictividad y desviación también serían menores. De hecho, en la competencia por la vida, la violación de la cooperación aumenta el índice de conflictividad y desviación.

La criminología crítica enfrenta al poder punitivo de las clases dominantes que dirigen la estructura política del Estado. Al respecto, Taylor, Walton y Young (1997) apuntan que en la génesis del crimen están íntimamente vinculadas las bases materialistas del capitalismo contemporáneo y sus estructuras jurídicas.

Como sostiene Quinney (1970), la crítica al poder punitivo reside en que la estructura capitalista de la sociedad permite que el Estado se organiza para servir los intereses de la clase económica dominante que tiene el control del gobierno utilizando la ley penal para conservar y perpetuar el statu $q u o$ y ejerciendo el control social con el fin de preservar el orden interno a través de instituciones y organismos que representan los intereses de dicha clase, los cuales deben mantener oprimidas a las clases subordinadas valiéndose de cualquier medio como la coerción y la violencia del sistema penal.

De lo anterior se desprende que la administración de justicia penal en manos de cuerpos colegiados de abogados que no son elegidos directamente por la población, sino mediante organizaciones como los colegios profesionales que han perdido su razón de ser como instituciones sociales representativas, resiente la idea de justicia como valor conducente a la paz social y resultan ser funcionales al sistema punitivo, porque refuerzan el carácter artificial del delito en contra de las clases vulnerables y mantienen la invisibilidad de los crímenes denominados de cuello blanco, pues la ansiedad e inquietud por la utilización del poder para explotar y someter a quienes se hallan en las posiciones sociales más desfavorecidas, ha caracterizado los principales sistemas políticos desde siempre como apunta Geis (s.f.).

\section{ANÁLISIS CRÍTICO DEL SISTEMA TOGADO DE ADMINISTRACIÓN DE JUSTICIA PENAL}

Consolidar un sistema de justicia penal asentado en la democracia no es sencillo debido a que la tradición inquisitorial que nos ha 
gobernado por siglos ha calado muy profundo en la conciencia colectiva de los operadores jurídicos. Con mucha razón, Foucault (1983) sostiene que:

\begin{abstract}
La acumulación de la riqueza y el poder de las armas, y la constitución del Poder Judicial en manos de unos pocos, es un único proceso que se fortaleció en la Alta Edad Media, y alcanzó su madurez con la formación de la primera gran monarquía medieval, en la segunda mitad del siglo XII. En este momento, aparecen una serie de fenómenos totalmente nuevos en relación con la sociedad feudal, el imperio Carolingio, y las antiguas reglas del Derecho Romano. [...] 1. Una justicia que no es más pleito entre individuos [...], 2. Aparece una figura totalmente nueva, que no tiene precedentes en el Derecho Romano: el procurador [...], 3. Aparece una noción absolutamente nueva: la infracción [...], 4. Aparece el gran mecanismo de las confiscaciones [...]. Las monarquias occidentales se fundaron sobre la apropiación de la justicia, que les permitía la aplicación de estos mecanismos de confiscación. He aquí el fondo político de esta transformación. (pp. 76-77)
\end{abstract}

Este modelo inquisitorial es un mecanismo de concentración de poder, antes al servicio de las monarquías absolutas y ahora al servicio del gobierno de turno influenciado por el clientelismo político que basa su existencia en una maquinaria burocrática cuyo protagonista principal es el juez, desplazando a los protagonistas reales del conflicto, imputado y víctima.

En este contexto la legitimidad de los jueces en relación con su imparcialidad al momento de resolver los conflictos se pone en duda, pues cuando dictan sus sentencias no deben favorecer al gobierno de turno o a algún grupo de poder.

Por otro lado, es evidente que la historia de la justicia en nuestro país es la historia de la debilidad e inoperancia de la ley, esto ha generado de igual forma un escepticismo social sobre el valor e importancia de la ley que genera el debilitamiento de los vínculos sociales con lo cual la sociedad pierde su fuerza para integrar y regular adecuadamente a los individuos pudiendo llegar a niveles de anomia, crítica situación social que han explicado Durkheim y Merton.

Sin embargo, esta debilidad legal no ha surgido en la actualidad, sino es producto del devenir histórico que nos remonta al Estado indiano donde se usó la ley para fortalecer al poderoso en contra de quienes efectivamente necesitaban recurrir a ella en busca de justicia.

Así se ha gestado nuestra cultura jurídica, teniendo como eje central la figura del juez, quien aparece en lo más alto de la escala conformando una élite o curia conocedora del saber jurídico y de los rituales procedimentales que informan el desarrollo del proceso penal. Esto nos hace rememorar el célebre cuento kafkiano Ante la ley que metafóricamente relata el papel que desempeñan los «guardianes de la ley» ante los ciudadanos, por ejemplo, los jueces, quienes lejos de brindar acceso a la justicia construyen trabas e incertidumbres frente a ellos generando interpretaciones o un lenguaje cada vez más ajeno a la razón.

Muchas veces la actuación judicial complica o confunde a quienes demandan tutela jurisdiccional creando un saber jurídico paralelo al que espera la ciudadanía, un saber jurídico que no se comprende, que no se entiende, que no es de fácil acceso para todos, que no es democrático ni inclusivo.

Este sistema judicial se construye sobre el concepto de infracción que reemplaza al concepto de conflicto y señala como más importante que el conflicto entre los ciudadanos al conflicto surgido entre el infractor y el Estado. Así, lo que interesa no es que Carlos haya matado a José sino que al hacerlo ha desobedecido al Estado infringiendo la ley, lo cual es la causa de su sanción penal.

Además, para lograr legitimidad el sistema se organiza mediante un cuerpo de profesionales del derecho: juzgadores, fiscales, procuradores, etc. de una manera vertical suponiendo que solo ellos pueden actuar justamente al haber estudiado leyes y principios jurídicos en sus respectivas facultades. Trasladando los conceptos jurídicos aprendidos en las aulas universitarias a los tribunales generando interpretaciones cada vez más abstractas y ajenas a la realidad, cosificando a los justiciables, creando una maquinaria 
de los países periféricos hispanoamericanos

The convenience to establish of the jury system in criminal justice of

hispanic americans peripheral countries

industrial de hacer justicia, despersonalizando y reduciendo la diversidad en aras de una simplificación de la razón que resulta más instrumental que humana.

No obstante, este sistema que aparenta ser sumamente organizado y estable al estar asentado en normas y procedimientos solemnes, conformado por un cuerpo profesional que utiliza un lenguaje sumamente técnico, es al contrario, enormemente débil, pues se apoya en una cúpula de poder que establece excepciones de acuerdo con su conveniencia política, y que no ha podido democratizar el poder que le fue otorgado por el pueblo.

El sistema de administración de justicia se configura a través de la interacción de sus actores, unos más fuertes (juez, fiscal, policía) y otros más débiles (imputado, víctima, tercero civil), sin embargo, mientras no exista una verdadera trasformación en el ámbito externo de dichos sistema poco se le logrará dentro de este.

Asimismo, no hay que perder de vista que la justicia penal sirve para regular de manera proporcional la intensidad de la violencia estatal frente a los ciudadanos, por ello es conveniente que la asignación de poder punitivo sea razonable al momento de la criminalización primaria, secundaria y terciaria evitando que dicha violencia quede apenas fundamentada en resoluciones judiciales, que el culto al trámite del expediente judicial se imponga frente a una justicia de carne y hueso, etc.

Por otro lado, es correcto afirmar que hoy en día existen ciertas «alianzas» entre algunos de los actores del sistema de administración de justicia, algunas legítimas (policía y fiscal) y otras no (juez y fiscal). También observamos la falta de control de los fiscales o jueces frente a la actividad policial, que muchas veces pretende justificarse por la sobrecarga laboral producto de tareas banales.

Asimismo, otro punto de suma importancia en el sistema de administración de justicia es el relacionado a la obtención de la verdad en el proceso penal, sobre todo la relación de esta con la función del juez. Creemos que el compromiso del juez con la verdad no lo habilita para buscarla, pues se la debe exigir al acusador. Sin embargo, en nuestro sistema observamos que muchas veces son los jueces, quienes, a través de medios probatorios de oficio, aportan los elementos probatorios pertinentes y útiles para resolver el caso.

Estos casos ponen de manifiesto el «activismo judicial» que desde hace algunos años viene influenciando la conducta de los jueces dentro de nuestro sistema, porque al gozar del poder discrecional de administrar justicia a menudo confunden su papel de sujeto imparcial dentro del proceso con el de parte activa del mismo. Creemos que ello también obedece a la marcada influencia de la tradición inquisitorial que será difícil de modificar en nuestra cultura jurídica.

En este orden de ideas, la misión del juez es valorar y apreciar los medios probatorios ofrecidos por las partes observando las reglas de la lógica, la ciencia y las máximas de la experiencia debiendo exponer los resultados obtenidos y los criterios adoptados. Ello importa la motivación clara, lógica y completa de cada uno de los hechos y circunstancias que se dan por probadas o improbadas, y la valoración de la prueba que la sustenta con indicación del razonamiento que la justifique. Además, deberá señalar los fundamentos de derecho con precisión de las razones legales, jurisprudenciales o doctrinales que sirvan para calificar jurídicamente los hechos y sus circunstancias, y para fundar el fallo.

En la actualidad la labor judicial recae únicamente en abogados, profesionales del Derecho formados en aulas universitarias donde se los educa sobre los principios, las normas jurídicas, la doctrina, la jurisprudencia, etc., es decir, con la finalidad de capacitarlos para interpretar justa y racionalmente las leyes, y con ello puedan resolver correctamente los conflictos interpersonales que se les presenten.

Sin embargo, creemos que no solamente los abogados tienen la capacidad de ser jueces, pues cualquier profesional, técnico o ciudadano de a pie, puede apreciar los hechos y valorar los medios probatorios aportados por las partes al proceso penal observando las reglas de la lógica, el sentido común, el conocimiento del género humano, el sentido de justicia y las máximas de la experiencia. Es más, en algunos casos un médico, contador o psicólogo estarían en mejores condiciones de juzgar ciertos hechos. Por ejemplo, un profesional de la salud estaría en mejor posición para valorar un delito 
contra la vida, el cuerpo y la salud, ya sea un homicidio, un aborto o lesiones. Asimismo, un contador podría apreciar mejor un delito de fraude contable o tributario.

Por otra parte, un juzgamiento oral y público, como el que se comete en nuestro sistema de administración de justicia es simple y concreto: jueces que atienden el litigio con inmediación y de manera concentrada; fiscales que habiendo investigado preparatoriamente el caso ofrecen medios de prueba para acreditar las afirmaciones realizadas en su acusación ante los juzgadores; acusado que defendido por su abogado contradice lo alegado por el fiscal, etc. Todo ello mediante un método de debate pacífico y dialéctico de fácil comprensión para cualquier ciudadano (presentación del caso, ofrecimiento y actuación de prueba y alegatos finales) que permite, al haber estado presente y atento, formarse la convicción necesaria para pronunciarse sobre la culpabilidad o no del acusado.

Con este juicio previo cualquier ciudadano, y no solo un abogado, puede formarse el criterio necesario para emitir una decisión amparada en una información ofrecida por las partes, y actuada con el respeto irrestricto del contenido esencial de los derechos fundamentales. Por consiguiente, no hay razón para sostener que tan solo abogados deban ser considerados para el cargo de jueces, pues con un juicio oral y público como el descrito cualquier ciudadano estaría en la condición de administrar justicia.

No existe un método científico para llegar a una sentencia justa en un proceso penal. La interpretación de las declaraciones de los acusados y de los testigos y la evaluación de la culpabilidad no tienen su base en normas, sino en el juez que aplica su lógica y también sus conocimientos y experiencia de vida. En esta comprensión no hay diferencias entre un jurista y un ciudadano común. (Brandt, 2013, p.136)

Además, un sistema de justicia exclusivamente conformado por jueces abogados siempre ha estado ligado con un modelo inquisitorial, por ello muchos autores de la Escuela Clásica Liberal del Derecho Penal plantearon la incorporación de jurados. Sin embargo, la tradición inquisitorial siempre la ha rechazado, pues sabe que no tiene lugar en una organización judicial con participación ciudadana, ya que al darle cabida a ciudadanos de a pie no contaría con los aliados para estar al servicio del poder.
Además, si el actual sistema pretende ser tomado en cuenta como un modelo acusatorio adversarial, necesita proporcionar información de calidad, lo cual solo será posible en la medida que tanto fiscales como abogados defensores se vean obligados a preparar sus casos de modo comprensible para cualquier ciudadano generando una mayor comprensión de toda la población sobre la finalidad del proceso que, como hemos sostenido anteriormente, debe constituirse como un método de debate pacífico y dialéctico que busca solucionar los conflictos entre las partes, y no como un conjunto de procedimiento para sancionar al acusado por haber desobedecido al Estado.

Como sostiene Brandt (2013):

En un Estado democrático el ciudadano no debería ser solo el objeto de la justicia sino también su sujeto. En el concepto ideal, el juez lego es representante del pueblo, que vigila el cumplimiento del debido proceso y es un garante de los principios de la oralidad y publicidad. Los jueces ciudadanos son los llamados a introducir en las deliberaciones de los tribunales los valores principales que rigen a la población y promover procedimientos transparentes y entendibles. Mediante el control social de los jueces profesionales se busca un acercamiento del Poder Judicial a la sociedad. De esta manera se quiere reforzar la confianza de la población en dicha institución. (p. 133)

La democratización de la justicia, a través de la participación tanto de ciudadanos comunes como de jueces, permite superar el centralismo judicial; se cambia el idioma extremadamente técnico por uno sencillo y cotidiano para permitir que la población, y sobre todo el acusado, entiendan los motivos de las decisiones adoptadas.

Resulta indudable que la incorporación del juicio por jurados disminuye la brecha entre la práctica judicial y la realidad social cotidiana. Además, elimina la idea de que la justicia solo puede ser administrada por abogados permitiendo la democratización del Poder Judicial que actualmente es el menos democrático de todos y comprometiendo a los ciudadanos con la resolución de los conflictos sociales lo cual ayuda a que la población comprenda de manera directa la importante función que cumple el proceso dentro del ordenamiento jurídico. 
de los países periféricos hispanoamericanos

The convenience to establish of the jury system in criminal justice of

hispanic americans peripheral countries

Sin embargo, la principal ventaja de incorporar jueces ciudadanos es disminuir la crisis de legitimidad que padece actualmente nuestro sistema de administración de justicia, pues los ciudadanos pueden controlar verdaderamente el amplio poder que hoy ostentan los jueces profesionales. En este sentido, hay que resaltar que las decisiones que se toman en el Poder Judicial no solo afectan a las partes en conflicto, sino que se relacionan directamente con la vida institucional de nuestra sociedad. Asimismo, los jurados ciudadanos sabrán de las implicancias y tensiones que surgen al tomar decisiones sujetas a presiones sociales, políticas, morales y mediáticas.

\section{HACIA UNA VERDADERA DEMOCRATIZACIÓN DE LA DEFINICIÓN, ASIGNACIÓN Y EJECUCIÓN DE LA CONDUCTA DESVIADA}

\section{La necesidad de justificar razonablemente el castigo}

La realidad muestra cómo el Estado, en materia de ejercicio del poder punitivo impone deliberada e irracionalmente dolor, sufrimiento y daño sin sentido racional alguno. ¿Alguien puede sostener válidamente que la pena de muerte, la cadena perpetua y las penas extendidas son razonables? ¿Alguno puede demostrar que en los centros penitenciarios se resocializa a la persona que ha infringido una norma? ¿Quién puede explicar convincentemente la inmensa cantidad de presos sin condena cumpliendo prisión preventiva? Esta situación hace que la imposición de una pena sea una oportunidad perdida para restablecer los lazos sociales entre el infractor, la víctima y la comunidad, lo cual es un aspecto importante que debería obligarnos a reflexionar si el actual sistema de justicia togada cumple democráticamente con sus fines.

En principio se advierte una desigualdad injustificada en favor de quienes controlan el poder y el sistema punitivo que define las conductas punibles; asigna y rotula a quienes deben ser procesados para ser castigados; y ejecuta las penas donde y como decide. ¿Es esto posible en una sociedad de iguales? ¿Es esto válido en un Estado democrático y de Derecho? ¿No es acaso el respeto a la dignidad de la persona humana el fin supremo de la sociedad y del Estado?
Indudablemente, por razones de control social, toda sociedad y el aparato estatal tienen el derecho de reprochar las faltas más graves cometidas por sus miembros, pero partiendo de la consideración de que todos somos iguales en dignidad y derechos como lo reconocen las constituciones políticas inspiradas en las ideas demoliberales. Entonces, ¿cómo justificar racionalmente el castigo impuesto por jueces no elegidos por la población?

Por lo general, los códigos penales se justifican en el fundamento filosófico utilitarista para imponer el castigo, en virtud del cual la pena garantiza el logro del beneficio social de la prevención, tanto general como especial, es decir, la pena se impone para que el infractor y las demás personas se inhiban de perpetrar la misma conducta infractora. Este mecanismo hace ver que se utiliza a la persona humana como un medio, cuando en realidad es un fin en sí mismo, por lo que no es válido para justificar el castigo. Además, en la realidad, las estadísticas demuestran palmariamente que este fundamento no es eficaz, pues el índice de criminalidad no se revierte sino, por el contrario, se incrementa.

También es usual acudir al retribucionismo como justificación, esto es, como el infractor ha causado un daño y un sufrimiento, entonces el estado en nombre del pueblo te provoca un daño y un sufrimiento. Sin embargo, este fundamento tiene la dificultad de no respetar el principio de proporcionalidad de la pena. De hecho, el hiperpunitivismo y el Derecho Penal del Enemigo así lo demuestran.

¿Cuál es entonces el fundamento justificatorio y legitimante más idóneo para imponer un castigo? Lo que debe sustentar la necesidad del reproche social en una sociedad de iguales es el compromiso de la comunidad con determinados valores, principios y normas de convivencia social. De esa manera, la expresión del desacuerdo social a través del reproche debe comunicar razones para convencer y no imponer miedo. ¿A alguien se adapta a golpes?

En la introducción hemos hecho referencia al precario índice de credibilidad de los poderes Legislativo, Ejecutivo y Judicial, así como de las agencias del sistema penal. Esto significa que el pueblo no asume como propio el actual sistema de producción normativa, su aplicación y ejecución. ¿Por qué no lo reconoce? Porque no son resultado de un proceso inclusivo y no traduce los intereses de la mayoría. 
Actualmente, el castigo a título de pena excluye en lugar de reintegrar. En efecto, resulta contradictorio que para «resocializar» a una persona que ha cometido una falta se la separe de la sociedad a través de la imposición de una pena privativa de la libertad.

Lo importante del castigo es reconocernos como iguales en una comunidad y proceder a la reconciliación después de la falta cometida, de esto se infiere que la misma comunidad debe participar real y personalmente en la elaboración del reproche social, porque el crimen no es un tema personal sino un lamentable problema comunitario que hay que resolver reconstructivamente con la participación del infractor, la víctima, la sociedad y el Estado.

\section{La necesidad de establecer el sistema de jurados y la conveniencia de planificar su funcionamiento}

La desigualdad social resulta un elemento incompatible con los principios democráticos $\mathrm{y}$, por consiguiente, la justicia togada es contraria al principio igualitario. La realidad demuestra que la población penitenciaria está compuesta en su inmensa mayoría por ciudadanos pertenecientes a las clases más desprotegidas y vulnerables de la sociedad. Además, la construcción social de la realidad que hacen los medios de comunicación induce a la población a pedir penas más duras. Este panorama penal adverso a una justificación racional del castigo debe ser reemplazado por una justicia administrada por ciudadanos no togados, elegidos al azar, para que actúen con deber cívico frente a la responsabilidad de ejercitar el reproche social. El nuevo sistema de jurado popular permitirá la formación de un acuerdo como consecuencia de la discusión inclusiva y genuina de todos los miembros del jurado, a diferencia de lo que ocurre con la justicia togada, en la que el juzgador no discute con nadie y, obviamente, no se pone en el lugar de la población, porque su condición profesional y rol funcional se lo impide, con lo cual el sentido de justicia sufre una distorsión.

¿Cuál es el sentido y la valía de un castigo duro por una infracción menor, como es el robo de un teléfono móvil cometido de noche por dos ciudadanos, frente a un peculado o una malversación de fondos millonaria cometida por un funcionario público o una especulación cometida por un empresario o una contaminación de ríos cometida por una empresa petrolera o minera? Huelgan comentarios porque en los países periféricos la justicia penal togada acostumbra a castigar severamente en el primer caso, mientras que el sistema invisibiliza los otros casos normalizando esas infracciones por la desigualdad social existente que ha perfilado nuestro derecho penal en uno selectivo, discriminador y violento.

Establecer el sistema de justicia penal por jurado popular significa reemplazar el sistema de justicia togada dirigido por élites jurídicas que producen resultados diferentes en nombre del pueblo, gracias a una formalidad vacía de contenido, pues el pueblo no ha participado. Esto supone, según Gargarella (2016), reconectar el derecho penal y la deliberación democrática sobre una base de autoridad moral, lo que quiere decir - citando a Murphy (2016) - que en ausencia de un cambio de estructuras sociales y económicas significativas, las sociedades modernas no tienen autoridad moral para castigar.

El pueblo, de quien emana el poder y por ende el poder de administrar justicia, debe involucrarse más en la creación, aplicación e interpretación de las normas penales, pues es lógico que así sea ya que el sistema democrático exige una participación decisiva en ello, máxime si se trata del uso de la fuerza del Estado contra el ciudadano, que es trascendental para su propia vida. Esta mayor participación que reclamamos desde aquí evitaría los sesgos no deseados en la justicia penal, a los que nos hemos referido precedentemente, tales como los prejuicios discriminatorios, los mitos sobre la malignidad del infractor, entre otros.

Hay, entonces, razones de peso para cambiar el sistema de justicia penal en favor del jurado popular como las motivacionales de legitimidad y las prácticas para reconocer el resultado deficitario del sistema de justicia penal togada, visible en el hecho de que pese a la multiculturalidad de las sociedades, las prisiones siguen siendo étnica y socialmente homogéneas, como anota Gargarella (2016), por lo que la decisión jurisdiccional tomada por uno, tres o cinco juzgadores profesionales no se justifica en la medida que no es producto de una discusión justa entre todos los potenciales afectados, entonces sería más imparcial promover la participación del pueblo mediante el sistema de jurados. 
The convenience to establish of the jury system in criminal justice of

hispanic americans peripheral countries

Evidentemente, en los estados periféricos hay históricamente tanta desigualdad, exclusión y elitismo que la población ha perdido la solidaridad y la fe en la justicia, de ahí que exista la necesidad de concienciar a la población y capacitarla cívicamente $\mathrm{y}$ en visiones de alteridad para que pueda intervenir democráticamente en temas de justicia formando parte de un jurado penal para que por primera vez tenga la responsabilidad de deliberar acerca de la responsabilidad de un conciudadano que ha cometido un delito y del castigo que se le debe imponer en nombre de todos.

\section{CONCLUSIONES}

El sistema de justicia penal en los países periféricos hispanoamericanos exhibe una histórica y permanente ilegitimidad, como consecuencia de la cual se desarticula al contrastarlo con la realidad, pues su operatividad real es diferente a la forma en que el discurso jurídico penal supone que opera $\mathrm{y}$, además, las agencias penales no operan conforme a la normatividad legal, por ejemplo, en el tema de los límites a la tipicidad, ni procesal, respecto de todos los autores de delitos.

Por el contrario, es un sistema de justicia que reparte dolor, reprime y se configura mediante el ejercicio del poder verticalizador y disciplinario sobre los sectores más carenciados de la población y algunos disidentes; por lo que resulta ser una ficción.

En efecto, dicho sistema no resocializa al infractor, no resarce a la víctima ni resuelve el conflicto, por el contrario, crea criminalidad, etiqueta $y$ estigmatiza, y olvida a la víctima, agravando y acumulando los conflictos en la sociedad.

Sin embargo, existe una incapacidad de reemplazarlo por otro sistema frente a la necesidad de defender los derechos de algunas personas debido a que tiene características estructurales de ejercicio de poder.

El sistema de justicia penal por jurados contribuye a una democratización de la justicia desterrando la tradición curialesca de los jueces profesionales, que va de la mano con el modelo inquisitivo que tanto atraso y daño han generado en el sistema de administración de justicia.

La incorporación de ciudadanos como jueces permite el control efectivo y directo a la función jurisdiccional encargada a los jueces profesionales, asimismo garantiza una administración de justicia entendible y sencilla para la población, lo cual coadyuva a un acercamiento fortaleciendo en legitimidad al sistema.

Es incorrecto afirmar que los jueces ciudadanos no pueden emitir resoluciones idóneas para resolver los conflictos que a su conocimiento se someten, pues para valorar los medios probatorios ofrecidos por las partes solo es necesario aplicar la lógica y las máximas de la experiencia adquiridas.

La administración de justicia penal en manos de cuerpos colegiados de abogados no elegidos directamente por la población, sino mediante organizaciones como los colegios profesionales que han perdido su razón de ser como instituciones sociales representativas afecta la idea de justicia como valor conducente a la paz social.

El sistema togado de justicia deviene funcional al sistema punitivo, porque robustece el carácter artificial del delito en contra de las clases vulnerables y coadyuva a la invisibilidad de los crímenes que afectan los intereses de la mayoría como los crímenes económicos, ambientales y aquellos denominados de cuello blanco.

El sistema de justicia penal por jurado sustenta mejor la necesidad del reproche social en una sociedad de iguales reflejando el compromiso de la comunidad con determinados valores, principios y normas de convivencia social; y expresando el desacuerdo social a través del reproche mediante la comunicación de razones para convencer y no para imponer miedo.

\section{REFERENCIAS}

Anitua, G. (2015). "Historias de los pensamientos criminológicos" ( $1^{\mathrm{a}}$ edición). Buenos Aires, Argentina: Ediciones Didot.

Brandt, H. (2013) "Participación ciudadana en la Justicia Penal: ¿Democratización o adorno inútil de los tribunales?'. En Revista Vox Juris, número 26, 129-154 pp. Perú.

Corporación Latinobarómetro. (2016). Informe 2016. Recuperado el 12 de julio de 2017 , de: http://gobernanza.udg.mx/sites/default/files/ Latinobar\%C3\%B3metro.pdf 
Diario Correo. (3 de octubre de 2015). El $85.1 \%$ rechaza al Congreso y $82.8 \%$ al Poder Judicial. Recuperado de: http://diariocorreo.pe/ politica/el-85-1-rechaza-al-congreso-y-82-8-alpj-622639/

Foucault, M. (1983). "La verdad y las formas jurídicas”. Barcelona, España: Eudeba.

Gargarella, R. (2016). “Castigar al prójimo. Por una refundación democrática del derecho penal" ( $1^{\text {a }}$. edición) Buenos Aires: Siglo Veintiuno Editores Argentina S.A.

Geis, G. (s.f.). "El delito de cuello blanco como concepto analítico e ideológico". Estados Unidos de América: Universidad de California. Recuperado el 10 de julio de 2017, de: http://egov.ufsc.br/portal/sites/default/ files/el_delito_de_cuello_blanco_como_concepto_ anlitico_e_ideologico.pdf

Mejía, M. (20 de septiembre de 2015). Tremenda desconfianza: opinión ciudadana sobre instituciones. El Comercio. Recuperado de: http://elcomercio.pe/politica/actualidad/ tremenda-desconfianza-opinion-ciudadanainstituciones-387489
Pavarini, M. (2010). “Control y dominación: teorías criminológicas burguesas y proyecto hegemónico". Buenos Aires, Argentina: Siglo Ventiuno Editores.

Proyecto de Opinión Pública de América Latina [LAPOP] (2015). "Perspectivas desde el Barómetro de Las Américas. La cultura política de la democracia en Las Américas: 2014." Recuperado el 25 de julio de 2017, de: http:// www.vanderbilt.edu/lapop/insights/IO908es_v3.pdf

Quinney, R. (1970). “The Social Reality of Crime”, Little, Berown \& Co., Boston, Estados Unidos de América.

Serrano Gómez, A. (s.f.). "La criminología crítica". España. Recuperado el 10 de julio de 2017, de: https:// www. google.com/search ? q=Dialnet LaCriminologiaEtica-46231++(5).pdf\&ie $=$ utf$8 \&$ oe $=u t f-8 \& c$ lient $=$ firefox $-b-a b \& g$ fe $\mathrm{rd}=$ cr\&ei=MvmQWayMHoqQ-gXNi414

Taylor, I.; Walton, P. y Young, J. (1997). “ $L a$ nueva criminología: contribución a una teoría social de la conducta desviada." Argentina: Amorrortu. 